\title{
Fractionating of Lemongrass (Cymbopogon citratus) Essential Oil by Vacuum Fractional Distillation
}

\author{
Dinh Nhat Do ${ }^{1, * \mathbb{C}}$, Dinh Phuc Nguyen ${ }^{1}$, Viet-Duc Phung ${ }^{2} \oplus$, Xuan-Tien Le ${ }^{3}$, Tuan Minh Le ${ }^{4}$, Van Manh Do ${ }^{4}$, \\ Bui Quang Minh ${ }^{5}$ and Xuan Cuong Luu ${ }^{6}$
}

1 Faculty of Environmental and Food Engineering, Nguyen Tat Thanh University, Ho Chi Minh City 700000, Vietnam; ndphuc@ntt.edu.vn

2 Future Materials and Devices Laboratory, Institute of Fundamental and Applied Sciences, Duy Tan University, Ho Chi Minh City 700000, Vietnam; phungvietduc@duytan.edu.vn

3 Department of Chemical Engineering, Ho Chi Minh City University of Technology, Ho Chi Minh City 700000, Vietnam; tien.le@hcmut.edu.vn

4 Institute of Environmental Technology, Vietnam Academy of Science and Technology, No. 18 Hoang Quoc Viet Road, Cau Giay District, Hanoi 122100, Vietnam; tuanlm@ietvn.vn (T.M.L.); dovanmanh@ietvn.vn (V.M.D.)

5 Center for Research and Technology Transfer, Vietnam Academy of Science and Technology, No. 18 Hoang Quoc Viet Road, Cau Giay District, Hanoi 122100, Vietnam; bqminh@cretech.vast.vn

6 Faculty of Drug, Cosmetic and Food, Dong An Polytechnic, 90, 30-4 Street, Binh Duong 75309, Vietnam; luuxuancuong@dongan.edu.vn

* Correspondence: ddnhat@ntt.edu.vn; Tel.: +84-933-230-134

Citation: Do, D.N.; Nguyen, D.P.; Phung, V.-D.; Le, X.-T.; Le, T.M.; Do, V.M.; Minh, B.Q.; Luu, X.C. Fractionating of Lemongrass (Cymbopogon citratus) Essential Oil by Vacuum Fractional Distillation. Processes 2021, 9, 593. https:// doi.org/10.3390/pr9040593

Academic Editor: Kostas A. Matis

Received: 4 March 2021

Accepted: 22 March 2021

Published: 29 March 2021

Publisher's Note: MDPI stays neutral with regard to jurisdictional claims in published maps and institutional affiliations.

Copyright: (c) 2021 by the authors. Licensee MDPI, Basel, Switzerland. This article is an open access article distributed under the terms and conditions of the Creative Commons Attribution (CC BY) license (https:// creativecommons.org/licenses/by/ $4.0 /)$.

\begin{abstract}
Lemongrass essential oil has many compounds appropriate for application in foods, cosmetics, and pharmaceutical products. Of these, citral is a high-value compound of interest to industry. This work aims to evaluate the use of vacuum fractional distillation to separate lemongrass essential oil compounds, producing essential oil fractions containing high citral content. The effect of process parameters, namely vacuum pressure, type column, and energy input, on the fractionation time, content, and recovery of citral in the fractions, was investigated. The fractionation of lemongrass oils successfully provided five fractions, i.e., fraction 1 (F1), fraction 2 (F2), fraction 3 (F3), fraction 4 (F4), and fraction 5 (F5). GC-MS (Gas Chromatography-Mass Spectrometry) spectra showed that the main compound contained in F1 and F2 fractions was $\beta$-myrcene ( $>70 \%)$. Meanwhile, F4 and F5 were the two main fractions for citral recovery. The optimal conditions of the fractional distillation system included a column height of $400 \mathrm{~mm}$, power input of $165 \mathrm{~W}$, and pressure of $15 \mathrm{mmHg}$. These conditions correspond to the highest total citral content of $95 \%$, with a recovery of $80 \%$ at the F4 and F5 fractions. Therefore, fractional vacuum distillation may be an effective method to upgrade lemongrass essential oil.
\end{abstract}

Keywords: lemongrass (Cymbopogon citratus); essential oils; fractional distillation; citral

\section{Introduction}

Lemongrass (Cymbopogon citratus), belonging to the Poaceae family, is a member of an important genus with about 120 species that crop up in tropical and subtropical areas around the world. It is widely planted over 16,000 ha throughout the world, which generates around $1000 \mathrm{t}$ of essential oil per year [1]. The lemongrass essential oil, extracted from the leaves, is commonly used in different pharmaceuticals, flavors, cosmetics, food preservation, and agriculture industries [2-5]. Recent scientific studies have indicated that diverse components in the lemongrass essential oil possess antioxidant [6,7], antimicrobial [8], antifungal [9], anti-inflammatory [10], anticancer potential [11], and mosquito repellent activities [12].

The major active components present in lemongrass essential oil are limonene, $\beta$ myrcene, citral, geraniol, citronellol, geranyl acetate, and neral nerol [13]. Although 
$\beta$-myrcene and limonene are aromatic composites, the main biologically active component of lemongrass essential oil is citral, a mixture of the isomeric acyclic monoterpene aldehydes neral (cis-citral) and geranial (trans-citral). Additionally, lemongrass's essential oil comprises small quantities of geraniol, geranyl acetate, and monoterpene olefins [14,15]. In general, lemongrass essential oil contains greater than $45 \%$ of citral, but the amount can vary widely depending on many different factors such as habitation, genetic diversity, weather, harvesting age, and extraction techniques [14,16,17]. The amount of citral is typically used to assess the quality of lemongrass essential oil. The higher the citral, the purer the essential oil [18-20]. According to ISO 3217:1974 standard, lemongrass essential oil should contain at least $75 \%$ of citral to be considered a product of quality. To ensure the quality of the essential oil, the technology of extraction and separation of the essential oil is critical. The selection of processes is mostly based on the chemical constitution, physicochemical natures, economic aspects, and the essential oil's intended application.

Commonly used methods for essential oil separation include solvent extraction, fractional distillation, and large-scale chromatography. The supercritical fluid extraction method using carbon dioxide solvent has been recently used to separate and purify essential oil. The method overcomes the disadvantages of traditional extractions that use organic solvents and generate a large amount of waste [21]. Supercritical fluid extraction procedures have been applied to natural products, especially in pharmaceutical technology. The system's prime advantage is its low operating temperature because the critical point of carbon dioxide is at $31^{\circ} \mathrm{C}$ and 73.8 bar. At this low temperature, the thermolabile compounds will not be destroyed, and the organoleptic properties of the extracts do not change [22]. The use of supercritical fluid extraction to segment and isolate pharmaceutical and chemical molecules from essential oil has been published in many studies, including fractional extraction for the removal of terpenes from citrus oil [23], increasing linalyl acetate concentration in a lavender essential oil [21], fractionation of dry ginger for production of high-quality volatile oil [24], fractions isolated from ten Salvia species [25], and fractionation of sterols, tools, and squalene in flaxseed oils [26]. Despite the fact that supercritical fluid extraction is known to be a clean technology giving fine yields and purity, the high operating pressure requires modern equipment and give rise to safety concerns and cost ineffectiveness. Large-scale chromatographic methods are not economically suitable for the separation of essential oil, so they are not usually used in spite of the rise of studies in this area [27]. The most common method for separating essential oil is fractionation distillation because of the operational simplicity and low costs. Batch vacuum distillation is commonly used because it operates at beginning temperatures and offers flexibility to work with various oils. The batch method's prime advantages are the flexibility and the possibility of working at a small scale, allowing performing of raw material assays before large-scale processing [28].

The fractional distillation method is based on differences in the volatility of compounds and depends on the physical and chemical features of the components and the pressure and temperature of the distillation process. The separation productivity also depends on the mass and energy transfer between the mixture's liquid and vapor phases. Thus, the packing type, diameter, and height of the packed column directly affect the outcomes [29]. Essential oils are a blend of terpenes and other volatile compounds. Most terpenes are thermally unsteady, decomposing, or oxidizing at high temperatures or in the presence of light or oxygen. Therefore, the distillation procedure is generally performed at vacuum pressures to decrease the volatile mixture's temperature of vaporization [30]. The vacuum fractional distillation to separate essential oil constituents is rarely reported, although it is widely used in the petrochemical industry. Farah et al. applied fractional distillation to work with Moroccan myrtle (Myrtus communis L.), improving the quality of the obtained fractions in correlation to the raw essential oil. The original essential oil contains three main active ingredients: $\alpha$-pinene $(10 \%), 1,8$-cineole $(43 \%)$, and myrtenyl acetate (25\%). This essential oil is divided into three segments: fraction 1 is rich in $\alpha$-pinene $(42-54.8 \%)$ and 1,8-cineole (27-53.6\%); fraction 2 is rich in 1,8-cineole (83-99.8\%); and 
fraction 3 contains more myrtenyl acetate (62-65\%) [31]. Silvestre et al. conducted a study on the fractional distillation of green mandarin essential oil (Citrus deliciosa Tenore). The obtained results demonstrate that fractional vacuum distillation is able to separate the hydrocarbon terpenes (recovered at the top of the column) from the terpenes with other chemical functions (alcohol, aldehydes, ketones, etc.), which remained in the bottom [30]. Researchers group led by Pauletti have reported using vacuum distillation to separate active ingredients of orange essential oil with interesting results. Most of the oxygenated functions remained in the bottom of the column, and the limonene mass percentage reduced from $96.68 \%$ to $52.81 \%$ in the bottom products [32]. In another study, D-limonene with $96.7 \%$ purity can be obtained by vacuum fractional distillation method with the pressure of $100 \mathrm{mmHg}$ and temperature of about $25-26^{\circ} \mathrm{C}$. D-Limonene content can be $99.9 \%$ purity with the help of silica gel adsorption technology [33]. Silvestre et al. also fractionated rosemary essential oil by fractional vacuum distillation. The light terpenes ( $\alpha$-pinene, myrcene, and camphene) were removed at the top of the column, while the oxygenated components (verbenone, borneol, linalool, and geraniol) remained at the bottom [34].

The quality of essential oil depends on many different factors; therefore, to ensure the essential oil's quality, it must be stabilized and standardized by separation technology. The separation using fractional distillation is necessary to raise the stability of the oil as well as its commercial value. Essential oils have many valuable applications. Nevertheless, if any individual compound has a high value, it is desirable to properly separate the admixture, increasing the original essential oil's value. In fact, pure constituents and fractions of the essential oil often express markedly stronger pharmacological features and hence have a far greater commercial value than the essential oil itself. Citral, which is the main ingredient in lemongrass essential oil, is a highly valuable product of interest to the industry. Due to the lack of information regarding lemongrass essential oil fraction, the aim of this work is to evaluate the use of fractional vacuum distillation to separate the compounds of the lemongrass essential oil. This work aims to assess the effects of vacuum pressure, type column, and energy input on the chemical profile of the obtained fractions during operation to produce essential oil fractions containing high citral content.

\section{Materials and Methods}

\subsection{Obtainment of Essential Oil}

Lemongrass (Cymbopogon citratus) raw essential oil was obtained by steam distillation method, provided by Aota International Company, located in Ho Chi Minh City, Vietnam. The essential oil was produced in January 2020, remained stored in an amber bottle, closed, in a cold chamber (temperature between 1 and $6{ }^{\circ} \mathrm{C}$ ). Before the fractionation progress, the raw oil essential was analyzed by GC-MS to identify it chemically.

\subsection{Description of the Vacuum Fractionation Distillation System}

The fractional distillation column was used to separate the essential oil from the plate column, which was made of glass with different heights of 200, 300, and $400 \mathrm{~mm}$. There was a flask made of glass in the column base, with a volume of $250 \mathrm{~mL}$, where the raw essential oil was added. The heating was provided by electrical resistances wrapped around the round-bottom flask. The electrical heating mantle in the bottom of the column was connected to a power controller to measure and regulate the heater's power (from 100-400 W). The system was connected to a vacuum pump (Edwards RV5F, BOC Edwards, West Sussex, UK) capable of low column pressure to $15 \mathrm{mmHg}$. This pump was connected with a vacuum pressure controller to measure and control the system's vacuum pressure. Mercury thermometers were used to monitor the temperature between stages, at the top and the bottom of the column. The condensed sample from each stage was collected in glass flasks connected to the column. The collected fractions were condensed and stored in containers that were kept $\operatorname{cool}\left(-5^{\circ} \mathrm{C}\right)$. 


\subsection{Fractionating Tests}

Distillation experiments were performed with samples collected from the top of the column and the flask. In each batch, $120 \mathrm{~mL}$ of raw oil essential was used. In each experiment, the vacuum pressure and heating rate of the flask were kept constant. When distillation experiments were performed, only vapor from the top of the column was gathered. Different oil fractions were recovered over time based on the differences in vapor temperature at the column's top. The distillation was carried out until the volume in the distillation flask was reduced to the minimum possible. The samples were immediately sent for qualitative and quantitative analysis. The tests were carried out in triplicate.

Factors affecting the fractional vacuum distillation of lemongrass essential oil, including vacuum pressure, type distillation column, and energy input (power of the heater), were examined in this study. First of all, the influence of fractionating type column was investigated by taking into account type column with different heights of 200, 300, and $400 \mathrm{~mm}$. Following that, the electrical heating mantle's power was also investigated, ranging from 100 to $400 \mathrm{~W}$, as well as considering vacuum pressure at 15,50, and $80 \mathrm{mmHg}$.

\subsection{Chromatographic Analysis}

The Gas Chromatography-Mass Spectrometry system (Thermo Fisher Scientific, Waltham, MA, USA) used to analyze the components contained in the essential oils of lemongrass was a Trace 1300 Thermo Scientific gas chromatography coupled with a TSQ 9000 mass spectrometer (Thermo Fisher Scientific, Waltham, MA, USA). The analytes were separated in a non-polar fused silica capillary column TG-5ms coated with methyl silicon (30 $\mathrm{m} \times 0.25 \mathrm{~mm}$ i.d.), $0.25 \mu \mathrm{m}$ film thickness (Thermo Fisher Scientific, Waltham, MA, USA) from Agilent. The MS scanning $\left(1 \mathrm{scan} \mathrm{s}^{-1}\right)$ was carried out in the mass range of 50-550 amu with electron impact ionization at $70 \mathrm{eV}$. Helium was used as the carrier gas at a flow rate of $1.2 \mathrm{~mL} \mathrm{~min}^{-1}$ in a split ratio of 1:250 $(0.2 \mu \mathrm{L})$. The column oven temperature was programmed as follows: (i) $60^{\circ} \mathrm{C}$ for $30 \mathrm{~s}$; (ii) rate of $6.0^{\circ} \mathrm{C} / \mathrm{min}$ from 60 to $180^{\circ} \mathrm{C}$; (iii) rate of $20{ }^{\circ} \mathrm{C} / \mathrm{min}$ from 180 to $220^{\circ} \mathrm{C}$ and hold for $5 \mathrm{~min}$. Most of the compounds present in lemongrass essential oils were identified by their mass spectra (NIST 2.2 library collection) and compared with Adams spectral library as a reference source. Individual peak areas were recorded, and the relative peak areas (\%) were computed to quantify fractional essential oil components. Chromatographic analyses were run in triplicate.

\section{Results and Discussion}

\subsection{Chemical Composition of Raw Lemongrass Essential Oil}

The results of analyzing the chemical composition of lemongrass lemon essential oil by GC-MS are presented in Table 1. $\alpha$-Citral (44.97\%), $\beta$-citral (33.06\%), and $\beta$-myrcene (7.68\%) were the major compounds of lemongrass essential oil. Unlike citrus essential oil, which is mostly composed of hydrocarbon terpenes, lemongrass essential oil has large amounts of aldehydes and ketones $(82.69 \%)$. The rest is the hydroterpenes $(9.9 \%)$ and small amounts of alcohols and esters. The results of this work show that the citral content of essential oils is higher than that reported by Manuel A. Falcão et al. (71.64\%) [35] and Kpoviessi et al. (75\%) [19]. Meanwhile, the myrcene content is distinct from the essential oil obtained in Benin (0\%) [19] and Nigeria (25.3\%) [36]. These large differences in the composition of essential oils may be explained by factors such as habitation, genetic variability, climate conditions, harvest time, and extraction techniques $[14,16,17]$.

\subsection{Influence of Vapor Pressure on Boiling Temperature of Lemongrass Essential Oil (Simulation by Aspen Plus V11)}

The boiling temperature of the main compounds in lemongrass essential oil at different pressure conditions was estimated through simulation using Aspen Plus V11 software (Aspentech, Bedford, MA, USA) (Figure 1). We can evaluate and predict the fraction distillation pattern of the raw lemongrass essential oil from this simulation result. 
Table 1. Chemical composition of raw lemongrass essential oil.

\begin{tabular}{ccc}
\hline RT (min) & Identified Compound & Area \% \\
\hline 5.1 & 6-Methyl-5-heptene-2-one & 2.72 \\
5.19 & $\beta$-Myrcene & 7.68 \\
6.12 & trans- $\beta$-Ocimene & 0.48 \\
6.34 & $\beta$-cis-Ocimene & 0.21 \\
7.44 & $\beta$-Linalool & 1.07 \\
8.62 & Citronellal & 0.41 \\
8.88 & Isoneral & 0.4 \\
9.28 & Isogeranial & 1.04 \\
9.88 & cis-Carveol & 0.18 \\
10.33 & cis-Geraniol & 0.11 \\
10.61 & $\beta$-Citral & 33.06 \\
10.9 & Geraniol & 1.98 \\
11.27 & $\alpha$-Citral & 44.97 \\
12.58 & cis- $\alpha$-Bergamotene & 0.36 \\
13.73 & Geranyl acetate & 1.09 \\
14.63 & Caryophyllene & 0.1 \\
14.91 & trans- $\alpha$-Bergamotene & 0.14 \\
16.07 & $\gamma$-Cadinene & 0.17 \\
17.99 & Selin-6-en-4 $\alpha$-ol & 0.28 \\
23.16 & m-Camphorene & 0.38 \\
23.51 & p-Camphorene & 0.18 \\
& Aldehydes and ketones & 82.69 \\
& Alcohols & 3.64 \\
& Esters & 1.09 \\
& Hydrocarbon terpenes & 9.9 \\
\hline
\end{tabular}

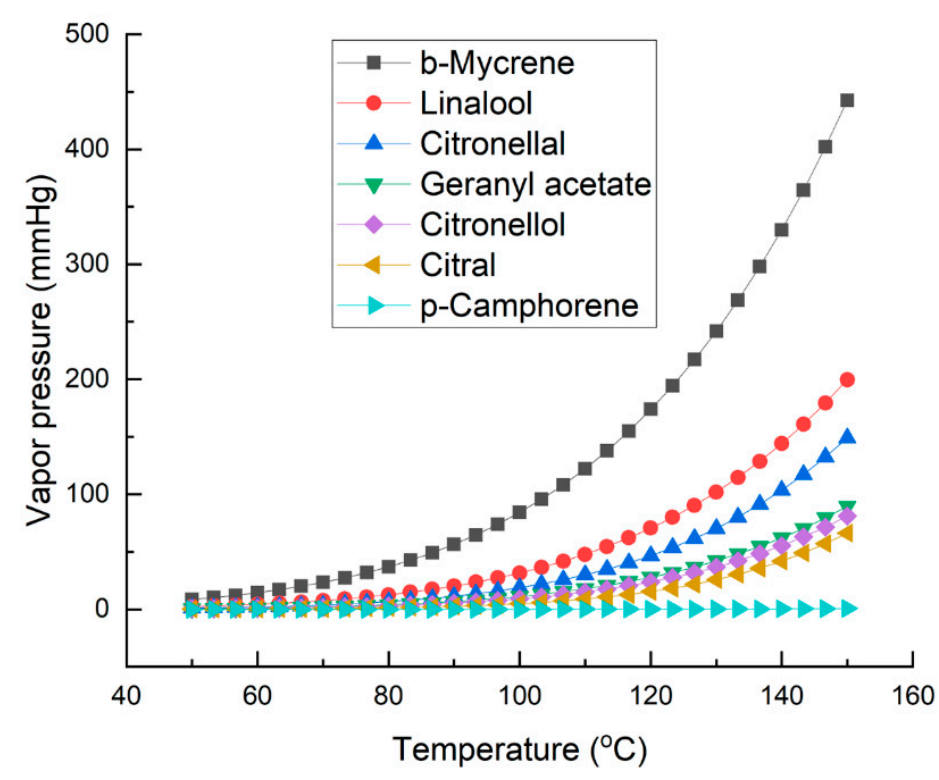

Figure 1. Temperature/pressure graph of the main components of lemongrass essential oil (simulation by Aspen Plus V11).

Figure 1 shows that the most volatile component is $\beta$-myrcene, as the vapor pressure was much higher than the rest. $\beta$-Myrcene together with (E)-hept-5-en-2-one (not shown in the figure) had the lowest boiling points among the ingredients of lemongrass essential oil; they were the first recovered from the top of the column during the distillation process. The boiling point of myrcene is $167^{\circ} \mathrm{C}$ at atmospheric pressure. At a vapor pressure less than $45 \mathrm{mmHg}$, its boiling temperature is less than $86^{\circ} \mathrm{C}$. When the vapor pressure reaches a value greater than $80 \mathrm{mmHg}$, the boiling temperature increases to greater than 
$100{ }^{\circ} \mathrm{C}$. Citral, the main ingredient of lemongrass essential oil, has a boiling point of $228^{\circ} \mathrm{C}$ at atmospheric pressure. When the vapor pressure increases from 5 to $45 \mathrm{mmHg}$, the boiling temperature will increase from 98 to $140{ }^{\circ} \mathrm{C}$. At a vapor pressure that is greater than $80 \mathrm{mmHg}$, its boiling temperature is higher than $157^{\circ} \mathrm{C}$. Compared with most other ingredients of lemongrass essential oil, citral has a higher boiling point, and it is more difficult to evaporate, so it will be recovered at the distillation's final stages. The least volatile ingredient is camphor, with a boiling temperature of $210{ }^{\circ} \mathrm{C}$ at $45 \mathrm{mmHg}$. The ingredient will remain at the bottom, not distilling through the column or, if distilling, in an extremely tiny portion.

At atmospheric pressure, the boiling temperatures of the main ingredients in lemongrass essential oil such as $\beta$-myrcene, $\beta$-linalool, geranyl acetate, citral, and camphor are $167,198,223,228$, and $357^{\circ} \mathrm{C}$, respectively. At these high temperatures, the essential oil is thermally unsteady, decomposing or oxidizing; therefore, the distillation procedure must be performed at vacuum pressures to decrease the temperature of the volatile mixture's vaporization, which avoids degradation of thermolabile compounds in lemongrass essential oil. During the distillation process, the hydrocarbon terpenes are usually recovered first because of the absence of functional groups to interact more firmly between molecules. However, different from citrus essential oil, which is mostly composed of hydrocarbon terpenes, lemongrass essential oil has large amounts of aldehydes and ketones (82.69\%), which are compounds with functional groups. Intermolecular interactions may affect the separation process thermodynamics, so the separation process can be more difficult [34]. In summary, the simulation results showed two major problems: first, because the difference in boiling points between $\beta$-myrcene and citral is large, it is feasible to separate raw oil into different fractions with high citral content. Second, because the boiling points of the ingredients in lemongrass essential oil are high, the separation process will be done at a high vacuum pressure to minimize the essential oil's thermal decomposition.

\subsection{Fractionating by Temperature (GC-MS Analysis)}

In the distillation tests, samples were collected at the top of the column at different temperature ranges (measured at the top of the column) and the remainder at the bottom of the column (end of the batch). The results of the qualitative and quantitative assessment (Table 2) showed the degree of separation in each distillate segment and its relation with the raw essential oil. As expected, the most volatile components of the lemongrass essential oil (sulcatone and $\beta$-myrcene) were the first to separate at the top of the column. Sulcatone was recovered almost completely in the first three fractions and was present at more than 4-7 times its initial concentration (from $2.72 \%$ in raw oil to $10.75,18.61,16.24 \%$ at the F1, F2, F3 fractions, respectively). $\beta$-Myrcene is the third most abundant ingredient in raw lemongrass essential oil $(7.68 \%)$ and among the most volatile active ingredients in essential oil. The fractional distillation was almost recovered in the first three fractions F1, F2, and F3 with a total recovery of $97 \%$ at the temperature ranges from $60-95{ }^{\circ} \mathrm{C}$. In particular, the content of $\beta$-myrcene in the F1 fraction (73.3\%) is about 10 times higher than that in crude essential oil. $\beta$-Myrcene is an active ingredient widely used in the fields of cosmetics, food, and beverages [37]. Hence, the F1 and F2 fractions with high $\beta$-myrcene content may have interesting potential for use in the aforementioned fields. The essential oil lemongrass is rich in citral (about 78 mass\% of the oil). Therefore, the fractionation could be easily performed to increase the citral content. In fact, there was a very clear difference in the citral content of the fractions. The citral content was negligible in the F1 and F2 segments. In the F3 segment, the citral content increased to 42\%. F4 and F5 were the two main fractions for citral recovery, with very high citral content of 92.7 and $94.6 \%$, respectively. The total recovery of citral in the two fractions F4 and F5 was about 80 mass\% at the temperature ranges from $98-110^{\circ} \mathrm{C}$. Such a distribution of the main constituents of lemongrass essential oil in the fractions was expected, due to the difference in boiling temperature of citral with other ingredients in the essential oil. According to the present outcome, it is evident that 
the separation of essential oil by fraction vacuum distillation could give the fraction with pure ( $>94$ mass $\%)$ citral, as well as fraction with a higher content of $\beta$-myrcene.

Table 2. Chemical composition and recoveries of the fractions of lemongrass essential oil.

\begin{tabular}{|c|c|c|c|c|c|c|c|c|c|c|c|c|}
\hline \multirow{2}{*}{ Compound } & \multirow{2}{*}{$\begin{array}{c}\text { Raw Oil } \\
(\mathbf{w t} \%)\end{array}$} & \multicolumn{2}{|c|}{$\begin{array}{c}\text { F1 } \\
60-64\end{array}$} & \multicolumn{2}{|c|}{$\begin{array}{c}\text { F2 } \\
65-70\end{array}$} & \multicolumn{2}{|c|}{$\begin{array}{c}\text { F3 } \\
71-95\end{array}$} & \multicolumn{2}{|c|}{$\begin{array}{c}\text { F4 } \\
98-107\end{array}$} & \multicolumn{2}{|c|}{$\begin{array}{c}\text { F5 } \\
108-110\end{array}$} & \multirow{2}{*}{$\begin{array}{c}\text { Overall } \\
\text { Recovery } \\
(\%)\end{array}$} \\
\hline & & $\begin{array}{c}\text { Average } \\
(\mathbf{w t} \%)\end{array}$ & $\begin{array}{l}\text { Recovery } \\
(w t \%)\end{array}$ & $\begin{array}{c}\text { Average } \\
\text { (wt \%) }\end{array}$ & $\begin{array}{c}\text { Recovery } \\
\text { (wt } \%)\end{array}$ & $\begin{array}{c}\text { Average } \\
\text { (wt } \%)\end{array}$ & $\begin{array}{c}\text { Recovery } \\
\text { (wt } \%)\end{array}$ & $\begin{array}{c}\text { Average } \\
\text { (wt } \%)\end{array}$ & $\begin{array}{c}\text { Recovery } \\
(w t \%)\end{array}$ & $\begin{array}{c}\text { Average } \\
(w t \%)\end{array}$ & $\begin{array}{c}\text { Recovery } \\
(w t \%)\end{array}$ & \\
\hline Sulcatone & 2.72 & 10.75 & 23.71 & 18.61 & 22.66 & 16.24 & 40.00 & 0.15 & 2.62 & - & - & 89.00 \\
\hline$\beta$-Myrcene & 7.68 & 73.30 & 57.27 & 48.30 & 22.01 & 20.69 & 18.05 & 0.08 & 0.49 & 0.02 & 0.05 & 97.87 \\
\hline$\beta$-Linalool & 1.07 & - & - & 2.00 & 6.54 & 2.50 & 15.65 & 1.60 & 71.03 & 0.01 & 0.19 & 93.41 \\
\hline Isogeranial & 1.04 & 0.19 & 1.10 & 0.18 & 0.61 & 3.47 & 22.35 & 1.41 & 64.40 & 0.32 & 6.09 & 94.55 \\
\hline$\beta$-Citral & 33.06 & 2.45 & 0.44 & 12.13 & 1.28 & 23.19 & 4.70 & 41.18 & 59.17 & 33.11 & 19.83 & 91.29 \\
\hline Geraniol & 1.98 & - & - & - & - & 0.96 & 3.25 & 2.52 & 60.45 & 2.86 & 28.60 & 92.30 \\
\hline$\alpha$-Citral & 44.97 & 4.22 & 0.56 & 11.79 & 0.92 & 19.30 & 2.88 & 51.59 & 54.49 & 61.50 & 27.08 & 95.00 \\
\hline $\begin{array}{l}\text { Geranyl } \\
\text { acetate }\end{array}$ & 1.09 & 0.09 & 0.50 & 0.07 & - & 0.01 & 0.06 & 0.86 & 37.48 & 1.92 & 34.88 & 87.88 \\
\hline
\end{tabular}

\subsection{Effect of Distillation Column on the Fractionation Time, Content, and Recovery of Citral in} the Fractions

In this experiment, the effect of the vacuum fractionation column length for fractionation time, content, and recovery of citral in the fractions was considered. This study's plate column was made of glass with different lengths of 200,300, and $400 \mathrm{~mm}$. The experiments were performed at a vacuum pressure of $15 \mathrm{mmHg}$, and the power input to the stove was $165 \mathrm{~W}$. Survey results showed that the higher the fractional column, the longer the fractional distillation time. Specifically, for columns with a height of $200 \mathrm{~m}, 300$, and $400 \mathrm{~mm}$, the total fractional time of compounds was 40,60, and $65 \mathrm{~min}$, respectively. Content and recovery of citral in different fractions for different types of columns are shown in Figure 2. For columns with a height of $200 \mathrm{~mm}$, although the fractional time was shorter, the degree of separation was the worst, resulting in citral content in segments F1 (14.53\%), F2 (28.02\%), F3 (63.36\%) being pretty high. For 300 and $400 \mathrm{~mm}$ columns, the separation was better, and the citral content in the early fractions was quite low. Overall, citral content and recovery were highest in the F4 and F5 fractions for all three types of columns. The higher the column, the greater the citral content in the F4 and F5 fractions. The average citral content of the 200, 300, and $400 \mathrm{~mm}$ columns in the F4, F5 segments was $89 \%, 91 \%$, and $93 \%$, respectively, with the total citral recovery in the two segments was about more than $80 \%$. For the column of $400 \mathrm{~mm}$, the highest citral content obtained was $94.61 \%$, with a recovery of $24 \%$ at the F5 fraction. This result was consistent with the study of Warsito et al. [38] that assessed the effect of a vacuum fractionation column length for fractions composition of citronella essential oil. The research team concluded that the higher the fractional column height, the better the separation and the higher the purity of the major components of citronella oil (citronellal, geraniol, and citronellol) obtained.

\subsection{The Effect of The Rate of Distillation Process on the Fractionation Time, Content, and Recovery of Citral in the Fractions}

In this experiment, the power input effect for fractionation time, content, and recovery of citral in the fractions was considered. The plate column used in this study was made of glass with a length of $400 \mathrm{~mm}$. The experiments were performed at a vacuum pressure of $15 \mathrm{mmHg}$ and the different power inputs of 100,165, 265, and $365 \mathrm{~W}$. When the stove's capacity was $100 \mathrm{~W}$, the energy was not enough to supply the essential oil fractionation, so the essential oil cannot pass through the distillation column. As the stove capacity increased from 165 to $365 \mathrm{~W}$, the distillation rate increased rapidly, and the fractional distillation time decreased rapidly from $65 \mathrm{~min}(165 \mathrm{~W})$ to $40 \mathrm{~min}(265 \mathrm{~W})$ and $22 \mathrm{~min}$ $(365 \mathrm{~W})$. The influence of power input on content and recovery citral in the fractions was shown in Figure 3. In general, when the distillation rate increased, the separation efficiency tends to decrease. At an input power of $165 \mathrm{~W}$, citral content in segment F1 was low at 6.6\%. Meanwhile, when the input power was 265 and $365 \mathrm{~W}$, citral content in the segment was 
higher (more than 10\%). Overall, the content and recovery of citral were highest in the F4 and F5 fractions for all three levels of input power levels. At fraction F5, the citral content obtained decreased gradually with increasing distillation rate, namely $94.61 \%, 93.54 \%$, and $92.34 \%$, respectively, with input power 165,265 , and $365 \mathrm{~W}$. This is probably because a greater distillation rate means a lower residence time. As a result, when the liquid and vapor phases had less contact time, the mass and energy transfer between the liquid and vapor phases of the mixture was also reduced, leading to reduced separation efficiency [29]. There was a slight difference in citral recovery at fractions when distillation was performed at different input powers. As the distillation rate increased, the total citral recovery in the F4 and F5 fractions increased. Total citral recovery increased from $81 \%(165 \mathrm{~W})$ to $85 \%$ $(265 \mathrm{~W})$ and $87 \%(365 \mathrm{~W})$. This may be because as the distillation rate increased, the heavier constituents in the essential oils evaporated faster, the more citral escaped from the column; it can be observed that the remaining citral content at the bottom of the column decreases when the distillation rate increased.

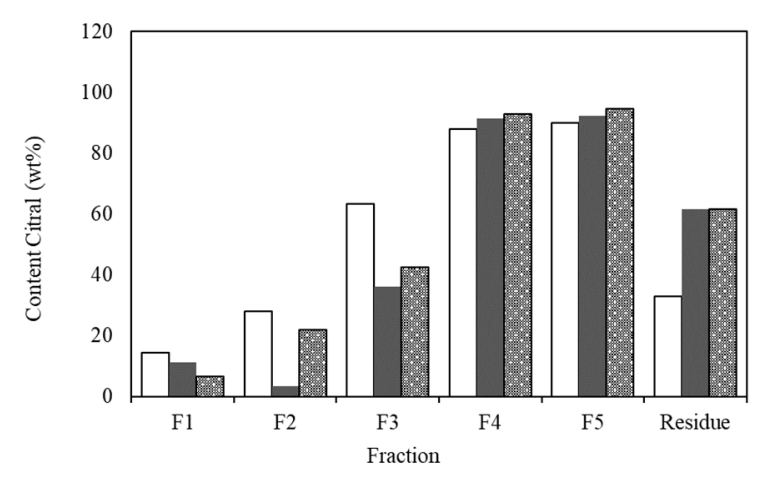

口Column $200 \mathrm{~mm}$-Column $300 \mathrm{~mm}$ - Column $400 \mathrm{~mm}$

(a)

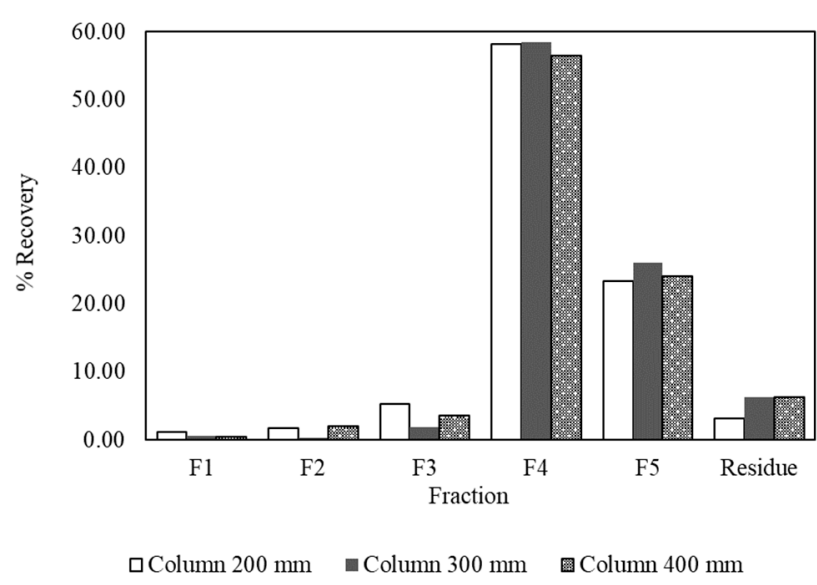

(b)

Figure 2. (a) Effect of distillation column on the content of citral in the fractions; (b) Effect of distillation column on the recovery of citral in the fractions.

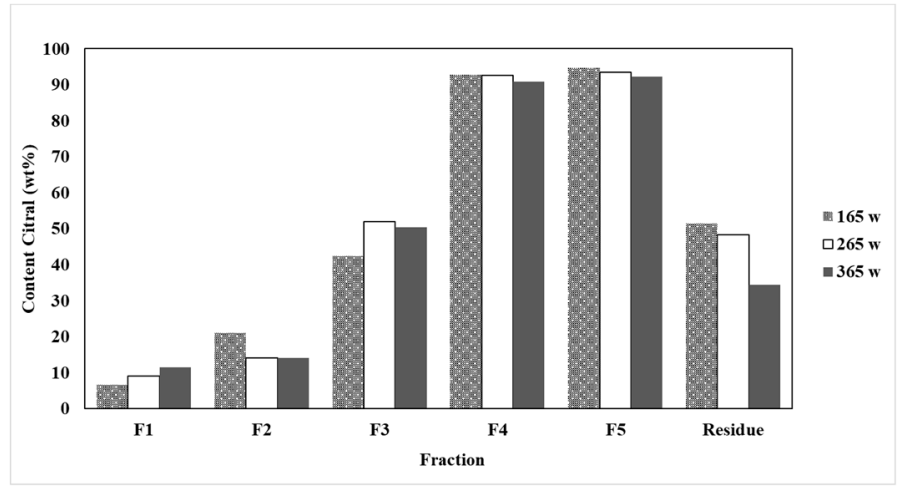

(a)

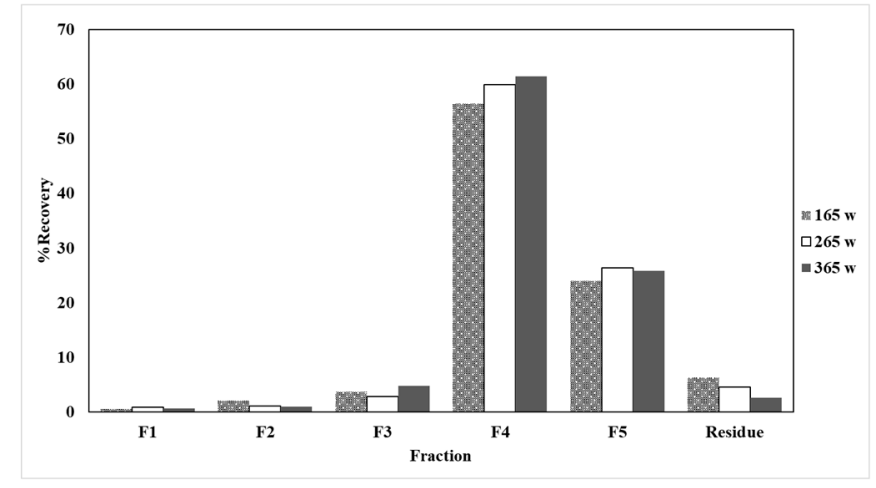

(b)

Figure 3. (a) Effect of the rate of distillation on the content of citral in the fractions; (b) Effect of the rate of distillation on the recovery of citral in the fractions.

3.6. The Effect of Vacuum Pressure on the Fractionation Time, Content, and Recovery of Citral in the Fractions

Essential oils generally are thermally unsteady, decomposing or oxidizing at high temperatures. Therefore, the distillation procedure was performed at vacuum pressures to 
decrease the temperature of the volatile mixture's vaporization, which avoided degradation of thermolabile compounds in essential oil. In this experiment, three different vacuum pressure levels of 80,50 , and $15 \mathrm{mmHg}$ were examined. Results indicate that a decrease in system pressure decreased the distillation time. At the lowest level of pressure $(15 \mathrm{mmHg})$, the total time for the fractionation of the compounds was $65 \mathrm{~min}$, while at $50 \mathrm{mmHg}$ pressure, it was $80 \mathrm{~min}$, and at $80 \mathrm{mmHg}$ pressure, it was $90 \mathrm{~min}$. At lower pressure, the boiling point of the solution decreased; at a pressure of $15 \mathrm{mmHg}$, the boiling point temperature in the fractions ranged from 60 to $110^{\circ} \mathrm{C}$, while at a pressure of $50 \mathrm{mmHg}$, it was $70-140{ }^{\circ} \mathrm{C}$, and at $80 \mathrm{mmHg}$, it was $80-150^{\circ} \mathrm{C}$. Lower operating pressure increased volatilization of the liquid mixture, thus accelerating the distillation process. The influence of vacuum pressure on content and recovery citral in the fractions was shown in Figure 4. In general, there was good separation performance under all three pressure conditions. At $50 \mathrm{mmHg}$, the citral content in the F4 (94.1\%) and F5 (95.1\%) segments was slightly higher when the system was operating at a pressure of $80 \mathrm{mmHg}$ (F4: 92.9\%, F5: 93.6\%) and pressure of $15 \mathrm{mmHg}$ (F4: 92.8\%, F4: 94.6\%). However, the total recovery of total citral in the F4 and F5 fractions at a pressure of $15 \mathrm{mmHg}(81 \%)$ was higher than that of pressure $50 \mathrm{mmHg}(74 \%)$ and $80 \mathrm{mmHg}(71 \%)$. Apparently, the vacuum pressure affected the fractional distillation time, and the lower the pressure, the shorter the operation time. This trend has been observed in Beneti et al. [28], investigating the effect of vacuum pressure on the fractionation of citronella essential oil and concentrated orange oil phase. Lower distillation time may be beneficial, in addition to higher productivity, the compounds of the essential oil exposed to high temperatures for shorter times, thus reducing possible thermal degradation. Besides the time factor, the operating pressure affected the ability to separate the active ingredient depended on the properties of the essential oils used. This has also been shown in the fractional distillation of citronella and orange essential oils as described above [28]. It has been indicated that the optimum pressure for fractionation of citronella oil was 5 mbar. While for concentrated orange oil fractionation, it was possible to obtain an optimum fraction at 10 mbar.

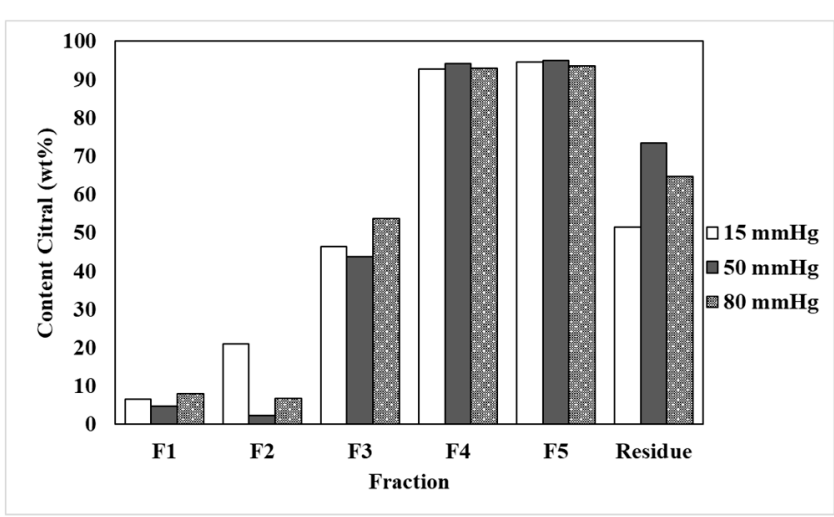

(a)

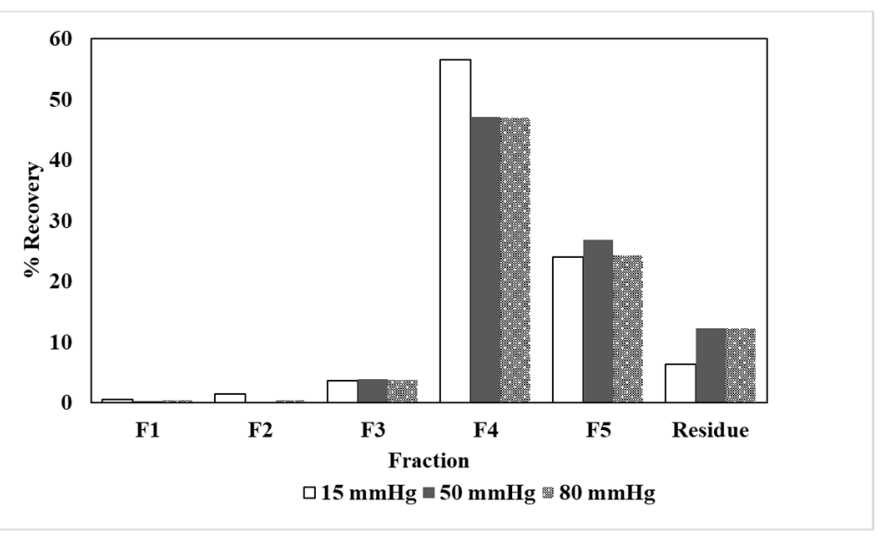

(b)

Figure 4. (a) Effect of vacuum pressure on the content of citral in the fractions; (b) Effect of vacuum pressure on the recovery of citral in the fractions.

\section{Conclusions}

In this study, the vacuum fractional distillation method was used to separate lemongrass essential oil. The effects of vacuum pressure, type column, and energy input on fractionation time, content, and citral recovery in the fractions were considered. The important obtained results indicated that the separation of the lemongrass essential oil under vacuum could be used for making essential oil fractions with high content and recovery citral. The fractional distillation system's optimal conditions included a column high of $400 \mathrm{~mm}$, power input of $165 \mathrm{~W}$, and pressure of $15 \mathrm{mmHg}$. These conditions correspond to 
the highest total citral content of $95 \%$, with a recovery of $80 \%$ at the F4 and F5 fractions. Besides, the fractional distillation also obtained fractions rich in $\beta$-myrcene (more than $70 \%$ ), which is widely used in the fields of cosmetics, food, and beverages. From the analysis of the obtained results, it can be concluded that fractional vacuum distillation is an effective method to improve the citral content and quality of lemongrass essential oil, contributing to enhancing the economic value of the lemongrass plant, an agricultural product that is widely grown in Vietnam.

Author Contributions: Investigation, D.N.D., D.P.N., T.M.L., B.Q.M., X.-T.L. and V.M.D.; Writingoriginal draft, D.N.D.; Writing-review \& editing, X.C.L. and V.-D.P. All authors have read and agreed to the published version of the manuscript.

Funding: This research received no external funding.

Data Availability Statement: Not applicable.

Acknowledgments: We would like to thank Nguyen Tat Thanh University, Ho Chi Minh City, Vietnam for the support of time and facilities for this study.

Conflicts of Interest: The authors declare no conflict of interest.

\section{References}

1. Haque, A.N.M.A.; Remadevi, R.; Naebe, M. Lemongrass (Cymbopogon): A review on its structure, properties, applications and recent developments. Cellulose 2018, 25, 5455-5477. [CrossRef]

2. Hanaa, A.M.; Sallam, Y.I.; El-Leithy, A.S.; Aly, S.E. Lemongrass (Cymbopogon citratus) essential oil as affected by drying methods. Ann. Agric. Sci. 2012, 57, 113-116. [CrossRef]

3. Abdulazeez, M.A.; Abdullahi, A.S.; James, B.D. Chapter 58-Lemongrass (Cymbopogon spp.) Oils. In Essential Oils in Food Preservation, Flavor and Safety; Preedy, V.R., Ed.; Academic Press: San Diego, CA, USA, 2016; pp. 509-516.

4. Ekpenyong, C.E.; Akpan, E.E. Use of Cymbopogon citratus essential oil in food preservation: Recent advances and future perspectives. Crit. Rev. Food Sci. Nutr. 2017, 57, 2541-2559. [CrossRef] [PubMed]

5. Avoseh, O.; Oyedeji, O.; Rungqu, P.; Nkeh-Chungag, B.; Oyedeji, A. Cymbopogon Species; Ethnopharmacology, Phytochemistry and the Pharmacological Importance. Molecules 2015, 20, 7438-7453. [CrossRef] [PubMed]

6. Fokom, R.; Adamou, S.; Essono, D.; Ngwasiri, D.P.; Eke, P.; Mofor, C.T.; Tchoumbougnang, F.; Fekam, B.F.; Zollo, P.A.; Nwaga, D.; et al. Growth, essential oil content, chemical composition and antioxidant properties of lemongrass as affected by harvest period and arbuscular mycorrhizal fungi in field conditions. Ind. Crop. Prod. 2019, 138, 111477. [CrossRef]

7. Guimarães, L.G.L.; dasGraças Cardoso, M.; Souza, P.E.; de Andrade, J.; Vieira, S.S. Antioxidant and fungitoxic activities of the lemongrass essential oil and citral. Rev. Ciênc. Agron. 2011, 42, 464-472. [CrossRef]

8. Adukwu, E.C.; Bowles, M.; Edwards-Jones, V.; Bone, H. Antimicrobial activity, cytotoxicity and chemical analysis of lemongrass essential oil (Cymbopogon flexuosus) and pure citral. Appl. Microbiol. Biotechnol. 2016, 100, 9619-9627. [CrossRef]

9. Tzortzakis, N.G.; Economakis, C.D. Economakis. Antifungal activity of lemongrass (Cympopogon citratus L.) essential oil against key postharvest pathogens. Innov. Food Sci. Emerg. Technol. 2007, 8, 253-258. [CrossRef]

10. Han, X.; Parker, T.L. Lemongrass (Cymbopogon flexuosus) essential oil demonstrated anti-inflammatory effect in pre-inflamed human dermal fibroblasts. Biochim. Open 2017, 4, 107-111. [CrossRef]

11. Sharma, P.R.; Mondhe, D.M.; Muthiah, S.; Pal, H.C.; Shahi, A.K.; Saxena, A.K.; Qazi, G.N. Anticancer activity of an essential oil from Cymbopogon flexuosus. Chem.-Biol. Interact. 2009, 179, 160-168. [CrossRef]

12. Tyagi, B.K.; Shahi, A.K.; Kaul, B.L. Evaluation of repellent activities of Cymbopogon essential oils against mosquito vectors of Malaria, Filariasis and Dengue Fever in India. Phytomedicine 1998, 5, 324-329. [CrossRef]

13. Kumar, V.; Tewari, R.; Singh, K. Comparative Studies of Drying Methods on Yield and Composition of the Essential Oil of Cymbopogon citratus. J. Essent. Oil Bear. Plants 2015, 18, 744-750. [CrossRef]

14. Verma, R.K.; Verma, R.S.; Chauhan, A.; Bisht, A. Evaluation of essential oil yield and chemical composition of eight lemongrass (Cymbopogon spp.) cultivars under Himalayan region. J. Essent. Oil Res. 2015, 27, 197-203. [CrossRef]

15. Mbili, N.C.; Opara, U.L.; Lennox, C.L.; Vries, F.A. Citrus and lemongrass essential oils inhibit Botrytis cinerea on 'Golden Delicious', 'Pink Lady' and 'Granny Smith' apples. J. Plant. Dis. Prot. 2017, 124, 499-511. [CrossRef]

16. Shaikh, M.N.; Suryawanshi, Y.C.; Mokat, D.N. Volatile Profiling and Essential Oil Yield of Cymbopogon citratus (DC.) Stapf Treated with Rhizosphere Fungi and Some Important Fertilizers. J. Essent. Oil Bear. Plants 2019, 22, 477-483. [CrossRef]

17. Tajidin, N.E.; Ahmad, S.H.; Rosenani, A.B.; Azimah, H.; Munirah, M. Chemical composition and citral content in lemongrass (Cymbopogon citratus) essential oil at three maturity stages. Afr. J. Biotechnol. 2012, 11, 2685-2693. [CrossRef]

18. Barbosa, L.C.A.; Pereira, U.A.; Martinazzo, A.P.; Maltha, C.R.Á.; Teixeira, R.R.; Melo, E.D.C. Evaluation of the Chemical Composition of Brazilian Commercial Cymbopogon citratus (D.C.) Stapf Samples. Molecules 2008, 13, 1864-1874. [CrossRef] 
19. Kpoviessi, S.; Bero, J.; Agbani, P.; Gbaguidi, F.; Kpadonou-Kpoviessi, B.; Sinsin, B.; Accrombessi, G.; Frédérich, M.; Moudachirou, M.; Quetin-Leclercq, J. Chemical composition, cytotoxicity and in vitro antitrypanosomal and antiplasmodial activity of the essential oils of four Cymbopogon species from Benin. J. Ethnopharm. 2014, 151, 652-659. [CrossRef]

20. Schaneberg, B.T.; Khan, I.A. Comparison of Extraction Methods for Marker Compounds in the Essential Oil of Lemon Grass by GC. J. Agric. Food Chem. 2002, 50, 1345-1349. [CrossRef]

21. Reverchon, E.; Porta, G.D.; Senatore, F. Supercritical CO2 Extraction and Fractionation of Lavender Essential Oil and Waxes. J. Agric. Food Chem. 1995, 43, 1654-1658. [CrossRef]

22. Reverchon, E. Supercritical fluid extraction and fractionation of essential oils and related products. J. Supercrit. Fluids 1997, 10, 1-37. [CrossRef]

23. Sato, M.; Goto, M.; Hirose, T. Fractional extraction with supercritical carbon dioxide for the removal of terpenes from citrus oil. Ind. Eng. Chem. Res. 1995, 34, 3941-3946. [CrossRef]

24. Shukla, A.; Naik, S.N.; Goud, V.V.; Das, C. Supercritical CO2 extraction and online fractionation of dry ginger for production of high-quality volatile oil and gingerols enriched oleoresin. Ind. Crops Prod. 2019, 130, 352-362. [CrossRef]

25. Wrona, O.; Rafińska, K.; Możeński, C.; Buszewski, B. Supercritical carbon dioxide extraction of Solidago gigantea Ait.: Optimization at quarter-technical scale and scale up the process to half-technical plant. Ind. Crops Prod. 2019, 130, 316-324. [CrossRef]

26. Dabrowski, G.; Czaplicki, S.; Konopka, I. Fractionation of sterols, tocols and squalene in flaxseed oils under the impact of variable conditions of supercritical CO2 extraction. J. Food Compos. Anal. 2019, 83, 103261. [CrossRef]

27. Kaltenbrunner, O.; Lu, Y.; Sharma, A.; Lawson, K.; Tressel, T. Risk-benefit evaluation of on-line high-performance liquid chromatography analysis for pooling decisions in large-scale chromatography. J. Chromatogr. A 2012, 1241, 37-45. [CrossRef]

28. Beneti, S.C.; Rosset, E.; Corazza, M.L.; Frizzo, C.D.; Di Luccio, M.; Oliveira, J.V. Fractionation of citronella (Cymbopogon winterianus) essential oil and concentrated orange oil phase by batch vacuum distillation. J. Food Eng. 2011, 102, 348-354. [CrossRef]

29. Wankat, P.C. Separation Process Engineering; Prentice Hall: Upper Saddle River, NJ, USA, 2017.

30. Silvestre, W.P.; Agostini, F.; Muniz, L.A.; Pauletti, G.F. Fractionating of green mandarin (Citrus deliciosa Tenore) essential oil by vacuum fractional distillation. J. Food Eng. 2016, 178, 90-94. [CrossRef]

31. Farah, A.; Afifi, A.; Fechtal, M.; Chhen, A.; Satrani, B.; Talbi, M.; Chaouch, A. Fractional distillation effect on the chemical composition of Moroccan myrtle (Myrtus communis L.) essential oils. Flavour Fragr. J. 2006, 21, 351-354. [CrossRef]

32. Perini, J.F.; Silvestre, W.P.; Agostini, F.; Toss, D.; Pauletti, G.F. Fractioning of orange (Citrus sinensis L.) essential oil using vacuum fractional distillation. Sep. Sci. Technol. 2017, 52, 1397-1403. [CrossRef]

33. Amanzadeh, Y.; Ashrafi, M.; Mohammadi, F. New Elaborated Technique for Isolation and Purification of Limonene from Orange Oil. Iran. J. Pharm. Sci. 2006, 2, 87-90.

34. Silvestre, W.P.; Medeiros, F.R.; Agostini, F.; Toss, D.; Pauletti, G.F. Fractionation of rosemary (Rosmarinus officinalis L.) essential oil using vacuum fractional distillation. J. Food Sci. Technol. 2019, 56, 5422-5434. [CrossRef]

35. Falcao, M.A.; Fianco, A.L.; Lucas, A.M.; Pereira, M.A.; Torres, F.C.; Vargas, R.M.; Cassel, E. Determination of antibacterial activity of vacuum distillation fractions of lemongrass essential oil. Phytochem. Rev. 2012, 11, 405-412. [CrossRef]

36. Kasali, A.A.; Oyedeji, A.O.; Ashilokun, A.O. Volatile leaf oil constituents of Cymbopogon citratus (DC) Stapf. Flavour Fragr. J. 2001, 16, 377-378. [CrossRef]

37. Bonamin, F.; Moraes, T.M.; Dos Santos, R.C.; Kushima, H.; Faria, F.M.; Silva, M.A.; Junior, I.V.; Nogueira, L.; Bauab, T.M.; Brito, A.R.S.; et al. The effect of a minor constituent of essential oil from Citrus aurantium: The role of $\beta$-myrcene in preventing peptic ulcer disease. Chem. Biol. Interact. 2014, 212, 11-19. [CrossRef]

38. Cahyani, C.; Cahayo, M. Effect of Column Length in Batch Vacuum Fractionation on The Distribution of Major Components of Citronella Oil (Cymbopogon winterianus). IOP Conf. Ser. Mater. Sci. Eng. 2019, 546, 022033. 